\title{
MODEL E-BUSINESS MENGGUNAKAN PIECES FRAMEWORK UNTUK PENINGKATAN DAYA SAING UMKM BERBASIS MOBILE APPLICATION
}

\author{
Noor Azizah \\ Fakultas Sains dan Teknologi, Program Studi Sistem Informasi \\ Universitas Islam Nahdlatul Ulama Jepara \\ Email: azizah@unisnu.ac.id \\ Buang Budi Wahono \\ Fakultas Sains dan Teknologi, Program Studi Teknik Informatika \\ Universitas Islam Nahdlatul Ulama Jepara \\ Email: budihono@unisnu.ac.id
}

\begin{abstract}
ABSTRAK
Usaha Kecil dan Menengah (UKM) merupakan salah satu bidang yang memberikan kontribusi yang segnifikan dalam memacu pertumbuhan ekonomi Indonesia. Di sisi yang lain, perkembangan teknologi dan internet juga berkembang sangat cepat. Oleh karena itu, pengelolaan bisnis dengan memanfaatkan teknologi digital yang ada saat ini menjadi bagian penting dalam meningkatkan daya saing UMKM agar mampu berkompetisi dengan pelaku industri yang lain. Tujuan dari penelitian ini adalah membangun sebuah $e$-business yang digunakan untuk meningkatkan performa bisnisnya dalam rangka mencapai keunggulan kompetitifnya agar mampu berdaya saing dengan para kompetitor. Tools yang digunakan untuk menganalisa kebutuhan sistem menggunakan PIECES Framework yang meliputi performance, informations, economics, control, efficiency, dan services. Adapun data primer diperoleh dari 50 responden untuk mengukur tingkat kepuasan penggunaan sistem e-business dalam pengelolaan bisnis UMKM. Hasilnya diperoleh rata-rata kepuasan pengguna, 3,92 yang artinya sistem $e$-business yang dikembangkan sangat penting dan pengguna merasa puas dalam penggunaan sistem tersebut.
\end{abstract}

Kata kunci: e-business, PIECES, UKM

\begin{abstract}
Small and Medium Enterprises (SMEs) is one of the fields that makes a significant contribution in spurring Indonesia's economic growth. On the other hand, the development of technology and the internet also developed very rapidly. Therefore, business management by utilizing existing digital technology is an important part in increasing the competitiveness of SMEs in order to be able to compete with other industry players. The purpose of this research is to build an e-business that is used to improve the performance of its business in order to achieve its competitive advantage in order to be able to compete with other competitors. Tools used to analyze system requirements using PIECES Framework which includes performance, information, economics, control, efficiency, and services. The primary data was obtained from 50 respondents to measure the level of satisfaction of the use of e-business systems in the management of SMEs businesses. The results are obtained by the average user satisfaction, 3,92 which means that the e-business system developed is very important and the user is satisfied in using the system.
\end{abstract}

Keywords: e-business, PIECES, SMEs 


\section{PENDAHULUAN}

UMKM merupakan sebuah usaha yang di manajemen oleh sekelompok masyarakat dan menjadi salah satu tonggak ekonomi bangsa Indonesia. Oleh karena itu, pengelolaan bisnis juga menjadi unsur penting dalam meningkatkan daya saing UMKM agar mampu berkompetisi dengan pelaku industri yang lain. Saat ini, perkembangan bisnis online sangat cepat sekali. Hal itupun juga dipengaruhi oleh perkembangan teknologi khususnya pada penggunaan fasilitas internet yang sekarang lebih mudah untuk pengaksesannya. [1]

Usaha Kecil dan Menengah (UKM) merupakan salah satu bidang yang memberikan kontribusi yang segnifikan dalam memacu pertumbuhan ekonomi Indonesia. Hal ini dikarenakan daya serap UKM terhadap tenaga kerja yang sangat besar dan dekat dengan rakyat kecil. Statistik pekerja Indonesia menunjukan bahwa 99,5\% tenaga kerja Indonesia bekerja di bidang UKM. Hal ini sepenuhnya disadari oleh pemerintah, sehingga UKM termasuk dalam salah satu fokus program pembangunan yang dicanangkan oleh pemerintah Indonesia. Kebijakan pemerintah terhadap UKM dituangkan dalam sejumlah Undang-undang dan peraturan pemerintah. [2]

Perkembangan UMKM yang saat ini terjadi sejajar dengan perkembangan teknologi maupun ICT yang ada. Pesatnya perkembangan teknologi informasi dan komunikasi atau yang sering disebut dengan istilah ICT (Information and Communication Technology) dan internet telah merambah dalam berbagai bidang kehidupan termasuk bidang bisnis dan perdagangan. Salah satu perkembangan yang sanat melonjak adalah penggunaan internet melalui perangkat mobile atau android. Dari data yang diperoleh, menunjukkan bahwa pengguna smartphone sudah mencapai 5 juta keatas. [3]

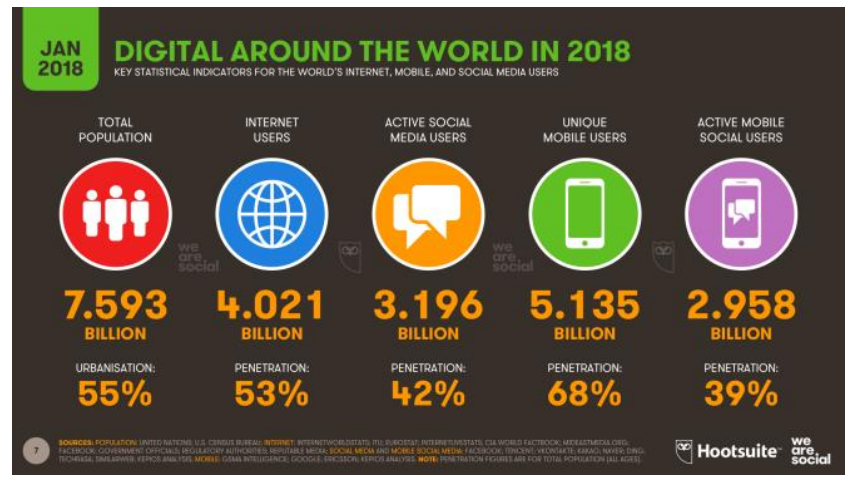

Gambar 1. Perkembangan Dunia Digital

Di era globalisasi seperti ini, UMKM harus mampu menggunakan ICT sebaik mungkin karena manfaatnya banyak sekali, diantaranya adalah (1) penghematan biaya pemasaran karena proses pemasaran saat ini sudah berbasis digital atau elektronik sehingga pengeluaran anggaran bisa seminimal mungkin namun efektifitas pemasaran produk pun tetap bisa tercapai; (2) mempercepat proses bisnis, karena dengan adanya teknologi berbasis internet dapat mengatasi permasalahan jarak dan waktu baik untuk proses transaksi antara penjual dan pembeli maupun pengelolaan rantai pasokannya; (3) mendapatkan informasi yang lebih cepat dan konektivitas secara global. Perolehan informasi yang cepat ini dapat membantu UMKM dalam menentukan keputusan lebih cepat. Selain itu jangkauan pasar pun bisa sampai dalam skala nasional maupun internasional.

Salah satu implementasi dari ICT di bidang perdagangan yaitu e-business, e-commerce, $e$ procurement, e-supply chian management dan lain-lain. Kesuksesan sebuah bisnis itu dapat diperoleh dari dua aspek yaitu efisiensi biaya dan kemampuan daya saing [4]. Dan cara untuk mencapai hal tersebut dapat dilakukan dengan peningkatan jangkauan pasar atau calon pelanggan dalam skala besar dan mendorong loyalitas pelanggan yang sudah ada. Selain itu juga pengurangan biaya melalui pemanfaatan layanan bisnis berbasis elektronik (digital). 
Pemanfaatan IT disini lebih berperan untuk mempermudah transaksi penjualan yang dilakukan secara online dan melakukan manajemen bisnis secara digital. Pemanfaatan teknologi yang tepat akan dapat meningkatkan kinerja perusahaan. Proses bisnis yang panjang, rumit dan membutuhkan waktu lama dapat menjadi lebih efisien dan membantu meminimalisir biaya. [5]

Pengelolaan UMKM yang baik sangat diperlukan untuk menghadapi tuntutan pasar global saat ini. Salah satu yang bisa dilakukan adalah menjualkan produknya yang memiliki nilai unggul dengan harga bersaing dan pengelolaan UMKM berbasis digital baik pada manajemen bisnis secara internal maupun penjualan ke customer

E-business merupakan salah satu contoh strategi yang bisa dilakukan untuk meningkatkan kemampuan daya saing UMKM melalui teknologi internet. E-business dapat diartikan sebagai pemanfaatan teknologi internet untuk meningkatkan kemampuan atau performa dari proses bisnis yang mencakup kegiatan penjualan dan pembelian produk atau jasa melalui situs website yang melibatkan stakeholder seperti konsumen, pemasok, pemilik usaha, dan vendor [6]. Selain itu $e$ business juga bisa dijadikan sebagai peluang besar bagi pelaku UMKM untuk bersaing di pasar global. Hal ini dilakukan untuk menampilkan keunggulan kompetitifnya [4].

Dalam melakukan kegiatan analisis dan evaluasi sistem informasi terdapat beberapa metode atau model analisis yang dapat digunakan, salah satunya yaitu menggunakan model analisis PIECES Framework. Untuk mempermudah proses analisis, dijelaskan cara analisis dengan kerangka PIECES yang menguraikan ke dalam 6 fokus analisis yaitu performance, information and data, economy, control and security, eficiency, dan service. Hasil analisis PIECES Framework merupakan dokumen kelemahan atau kekurangan sistem yang menjadi rekomendasi untuk perbaikan yang harus dikerjakan pada sistem yang akan dikembangkan lebih lanjut untuk perbaikan dari sistem sebelumnya [7].

Adapun tujuan dari penelitian ini adalah: (a) Mengidentifikasi kebutuhan dasar sistem untuk membangun sebuah e-business, (b) Menghasilkan model e-business berbasis mobile application untuk pengelolaan UMKM dalam rangka meningkatkan daya saing UMKM, (c) Mengetahui tingkat kepentingan dan kepuasan pengguna dalam penggunaan sistem.

\section{METODOLOGI PENELITIAN}

\subsection{PIECES Framework}

PIECES Framework adalah sebuah framework yang berisi tentang kategori-kategori pengklasifikasian masalah dan merumuskan pemecahan dari masalah tersebut. Klasifikasi itu dibagi menjadi enam kategori, yaitu Performances, Informations, Economics, Control, Efficiency, dan Services [8]. Berikut merupakan penjelasan dari ke enam kategori PIECES:

Tabel 1. Domain PIECES

\begin{tabular}{|c|c|c|}
\hline No & Domain & Keterangan \\
\hline 1 & Performance & $\begin{array}{l}\text { Sebuah analisis untuk mengetahui kinerja dari sistem, apakah } \\
\text { berjalan dengan baik atau tidak }\end{array}$ \\
\hline 2 & Information & $\begin{array}{l}\text { Analisis kebutuhan akan hal informasi yang dihasilkan oleh sebuah } \\
\text { sistem }\end{array}$ \\
\hline 3 & Economic & $\begin{array}{l}\text { Analisis yang dilakukan untuk mengetahui apakah sebuah sistem } \\
\text { tepat diterapkan pada sebuah lembaga informasi dilihat dari sisi } \\
\text { finansial dan biaya yang dikeluarkan oleh lembaga }\end{array}$ \\
\hline 4 & $\begin{array}{l}\text { Control and } \\
\text { Security }\end{array}$ & $\begin{array}{l}\text { Sebuah analisis yang dilakukan untuk mengetahui sejauh mana } \\
\text { tingkat pengawasan dan keamanan yang diterapkan agar sistem } \\
\text { berjalan dengan baik }\end{array}$ \\
\hline 5 & Efficiency & $\begin{array}{l}\text { Analisis terhadap sistem pada hal efisiensi baik pada sumber daya } \\
\text { dan proses }\end{array}$ \\
\hline
\end{tabular}




\section{Service Analisis terhadap layanan yang dilakukan sistem terhadap penggunanya}

\subsection{Metode Pengumpulan Data}

\subsubsection{Observasi}

Pengumpulan data dilakukan di UMKM Kopi Muria "You Soeka" yang beralamatkan di Dukuh Pandak Rt. 04 Rw.03 Desa Colo Dawe Kudus. Data yang diambil pada kegiatan observasi tersebut meliputi alur bisnis yang berjalan, data transaksi penjualan, dan data produk. Kegiatan observasi ini dilaksanakan guna menemukan keadaan yang sebenarnya di lapangan.

\subsubsection{Kuesioner}

Pengambilan data melalui penyebaran angket dilakukan untuk mencari hasil penilain dari implementasi aplikasi $e$-business. Jumlah sampel yang digunakan untuk penelitian ini berjumlah 50 orangyang terdiri dari pengelola UMKM dan konsumen dari produk UMKM. Adapun variabel yang digunakan dalam kuesioner adalah pernyataan dari PIECES Framework yaitu performance, information, economic, control and security, efficiency, dan service. Kuesioner terdiri dari 17 pertanyaan dari 6 domain PIECES Framework. Tabel 2. menunjukkan jumlah dan daftar pertanyaan dalam kuesioner.

Tabel 2. Daftar Pertanyaan Domain PIECES

\begin{tabular}{|c|c|c|}
\hline No & Domain & Pertanyaan \\
\hline 1 & Performance & $\begin{array}{l}\text { 1. Sistem e-business mudah diakses oleh pengguna } \\
\text { 2. Sistem e-business dapat mengoperasikan sejumlah } \\
\text { perintah dalam waktu yang relatif singkat } \\
\text { 3. Sistem e-business jika diakses secara bersamaan, } \\
\text { kinerja sistem tetep berjalan stabil }\end{array}$ \\
\hline 2 & Information & $\begin{array}{l}\text { 1. Informasi yang dihasilkan oleh sistem e-business, } \\
\text { sudah sesuai dengan yang dibutuhkan } \\
\text { 2. Informasi yang dihasilkan oleh sistem e-business, } \\
\text { tepat pada waktunya } \\
\text { 3. Informasi yang dihasilkan oleh sistem e-business, } \\
\text { mudah dipelajari dan dipahami } \\
\text { 4. Informasi yang dihasilkan oleh sistem e-business, } \\
\text { dapat diandalkan dan dipercaya }\end{array}$ \\
\hline 3 & Economic & $\begin{array}{l}\text { 2.1. Biaya yang dikeluarkan menjadi lebih ringan } \\
\text { dengan adanya sistem e-business dibandingkan } \\
\text { dengan cara konvensional } \\
\text { 2.2. Terdapat perubahan yang signifikan dalam } \\
\text { hal perkembangan dan pertumbuhan dengan adanya } \\
\text { sistem } e \text {-business }\end{array}$ \\
\hline 4 & $\begin{array}{l}\text { Control and } \\
\text { Security }\end{array}$ & $\begin{array}{l}\text { Sebuah analisis yang dilakukan untuk mengetahui } \\
\text { sejauh mana tingkat pengawasan dan keamanan yang } \\
\text { diterapkan agar sistem berjalan dengan baik }\end{array}$ \\
\hline 5 & Efficiency & $\begin{array}{l}\text { Analisis terhadap sistem pada hal efisiensi baik pada } \\
\text { sumber daya dan proses }\end{array}$ \\
\hline
\end{tabular}


6 Service

Analisis terhadap layanan yang dilakukan sistem terhadap penggunanya

Sedangkan untuk menghitung tingkat kepuasan dari hasil kuesioner, peneliti menggunakan skala likert seperti Tabel 3 berikut ini :

Tabel 3. Skala Likert Tingkat Kepentingan

\begin{tabular}{clcc}
\hline No & \multicolumn{1}{c}{ Jawaban } & Skor & Range Nilai \\
\hline 1 & Sangat Setuju & 5 & $4,5-5$ \\
2 & Setuju & 4 & $3,4-4,91$ \\
3 & Ragu-Ragu & 3 & $2,6-3,39$ \\
4 & Tidak Setuju & 2 & $1,8-2,59$ \\
5 & Sangat Tidak Setuju & 1 & $1-1,79$ \\
\hline
\end{tabular}

\subsection{Model Pengembangan Sistem}

Pengembangan aplikasi e-business berbasis mobile ini menggunakan pendekatan model waterfall [9]. Model Waterfall merupakan model yang paling populer dan sering dianggap sebagai pendekatan klasik dalam daur hidup pengembangan sistem. Pada metode waterfall terdapat 6 tahapan seperti yang digambarkan pada Gambar 2, yaitu: analysis, requirements specification, design, implementation, testing and integration, operation and maintenance.

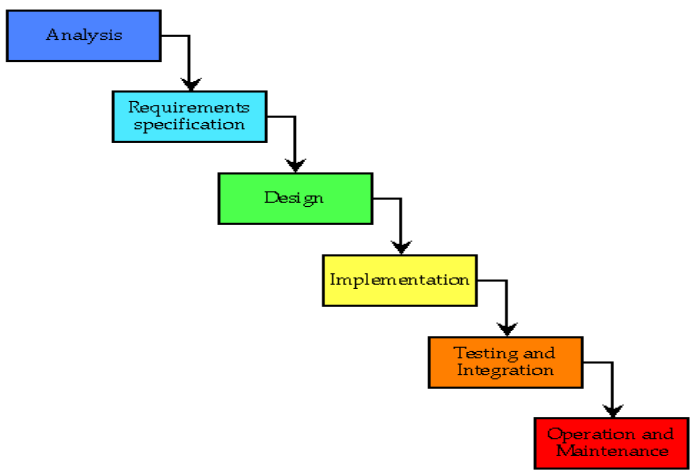

Gambar 2. Tahapan Model Waterfall

Tahapan pengembangan sistem yang akan kita bangun meliputi beberapa tahapan antara lain:

a. Analisis

Pada tahap ini dilakukan analisa terhadap objek penelitian. Kegiatan yang dilakukan adalah:

1) Analisis kebutuhan data dan informasi

Yaitu menganalisis data apa saja yang diperlukan dan informasi apa saja yang akan dihasilkan dari pengolahan data yang ada. Selain itu juga menganalisis kebutuhan software yang digunakan untuk membuat permodelan serta membangun sistem.

2) Analisis kebutuhan sistem

Yaitu menganalisis dalam rangka pembangunan aplikasi $e$-business berbasis mobile, adapun kegiatan yang dilakukan pada tahap ini adalah : 
a. Mengidentifikasi masalah yang ada pada proses bisnis UMKM

b. Mengidentifikasi kebutuhan teknologi informasi untuk meningkatkan daya saing UMKM di bidang pengelolaan bisnisnya

b. Perancangan

Perancangan sistem merupakan tahapan inti dari sebuah rancang bangun sebuah proses. Pada tahap ini dilakukan penyusunan rancang bangun aplikasi e-business berbasis mobile. Perancangan sistem ini, berfokus pada bagaimana merancang sebuah struktur data di dalam sistem, arsitektur perangkat lunak, representasi interface, dan detail (algoritma) prosedural. Adapun rancangan arsitektur sistem seperti pada Gambar 3.

c. Implementasi

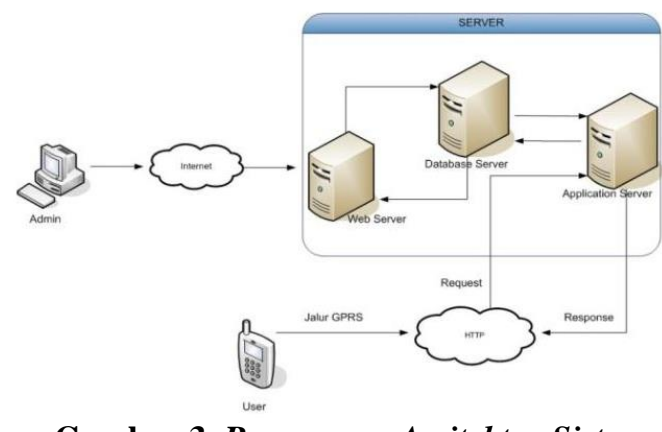

Gambar 3. Rancangan Arsitektur Sistem

Merupakan tahapan yang dilakukan untuk menyelesaikan desain sistem yang sudah dirancang. Dalam hal ini dilakukan pembuatan aplikasi e-business berbasis mobile yang akan diimplementasikan pada perangkat android.

d. Pengujian

Setelah aplikasi selesai dibangun, maka tahapan berikutnya adalah menguji aplikasi tersebut dengan cara menguji cobakan pada beberapa sample user untuk memastikan bahwa sistem yang kita bangun tidak ada permasalahan. Pengujian dilakukan pada uji validitas sistem menggunakan blackbox testing dan uji usability.

e. Perawatan

Perawatan terhadap sistem juga dilakukan setelah aplikasi tersebut dapat dijalankan. Tujuannya adalah agar aplikasi tersebut selalu up to date terhadap pertamahan data.

\section{HASIL DAN PEMBAHASAN}

Pada tahap analisis permasalahan dan kebutuhan sistem berdasarkan PIECES Framework, diperoleh hasil bahwa UMKM masih lemah dengan pengelolaan bisnisnya. Adapun hasil analisa masalah di lapangan, tertuang pada Tabel 4.

Tabel 4. Hasil Analisis Proses Bisnis Lama

\begin{tabular}{ccl}
\hline No & Domain & \multicolumn{2}{c}{ Pertanyaan } \\
\hline 1 & Performance & $\begin{array}{l}\text { Semua proses bisnis masih menggunakan cara } \\
\text { konvensional. Transaksi penjualan masih dilakukan } \\
\text { dengan bertemu langsung. Pencatatan administrasi dan }\end{array}$
\end{tabular}




\begin{tabular}{|c|c|c|}
\hline & & $\begin{array}{l}\text { keuangan masih ditulis dalam buku dan belum } \\
\text { terdokumentasikan dengan baik }\end{array}$ \\
\hline 2 & Information & $\begin{array}{l}\text { Informasi yang dihasilkan belum bisa dihasilkan secara } \\
\text { up to date karena menunggu pengerjaan dan } \\
\text { penghitungan manual. Selain itu, penyampaian informasi } \\
\text { juga masih secara langsung bertemu orang yang } \\
\text { bersangkutan langsung maupun melalui telepon. }\end{array}$ \\
\hline 3 & Economic & $\begin{array}{l}\text { Pelaku bisnis membutuhkan waktu yang banyak untuk } \\
\text { melakukan transaksi bisnis nya. Kemudian, pelanggan } \\
\text { juga membutuhkan waktu dan dana yang lebih untuk } \\
\text { memperoleh produk UMKM }\end{array}$ \\
\hline 4 & Control and Security & $\begin{array}{l}\text { Kontrol bisnis belum dilaksanakan dengan semaksimal } \\
\text { mungkin. Jadi belum bisa mengontrol jikalau ada } \\
\text { redundansi atau kehilangan data }\end{array}$ \\
\hline 5 & Efficiency & $\begin{array}{l}\text { Selama menggunakan cara bisnis konvensioanl, waktu } \\
\text { dan biaya lebih banyak terhabiskan. Selain itu butuh } \\
\text { SDM lebih banyak }\end{array}$ \\
\hline 6 & Service & $\begin{array}{l}\text { Pelayanan bisnis yang berjalan di UMKM masih lamban } \\
\text { dan belum profesional. }\end{array}$ \\
\hline
\end{tabular}

Dari hasil tersebut, maka dibuatlah sistem e-business berbasis Android untuk memudahkan para pelaku UMKM dalam mengelola bisnisnya. Pada aplikasi e-business ini akan mengelola penjualan produk dan manajemen bisnis UMKM. Gambar 4 menunjukkan halaman home untuk customer.

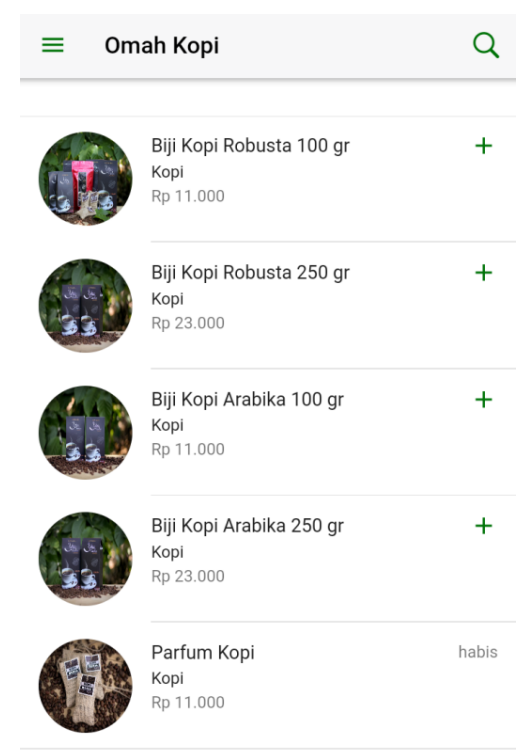

Gambar 4. Halaman Home untuk Customer 
Pada menu ini, pengguna yang berperan sebagai pembeli dapat mencari produk dengan mengklik icon ${ }^{\mathrm{Q}}$ (search), ketika pengguna ingin menambahkan barang ke dalam keranjang maka pengguna harus mengklik icon yang ada di bagian kanan list produk, sehingga icon akan tampil di sebelah kanan icon search sebagai notifikasi berapa jumlah produk yang dibeli. Halaman 5 menunjukkan halaman keranjang untuk customer.

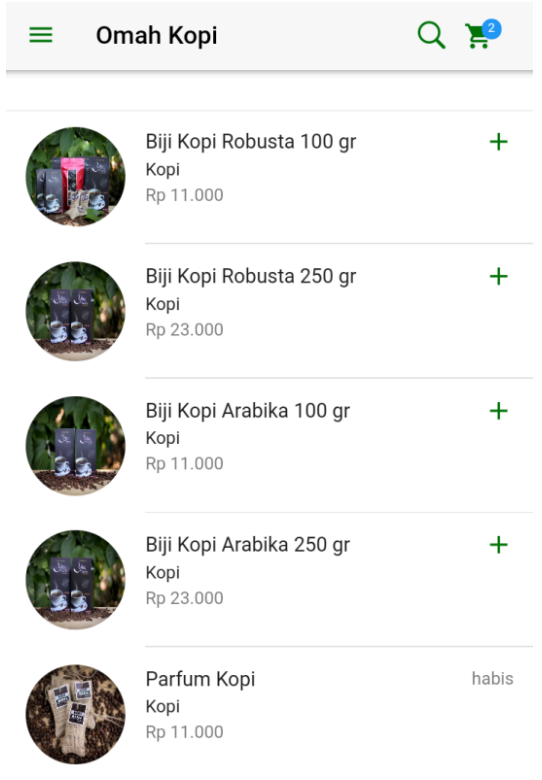

Gambar 5. Halaman Menu Keranjang untuk Customer

Pada menu ini, pengguna yang berperan sebagai pembeli dapat melihat keranjang dengan

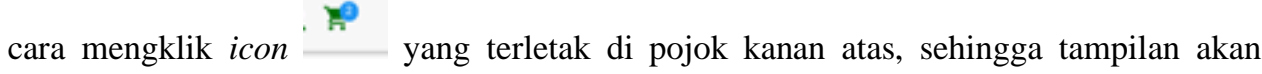
berubah seperti gambar 6 . 


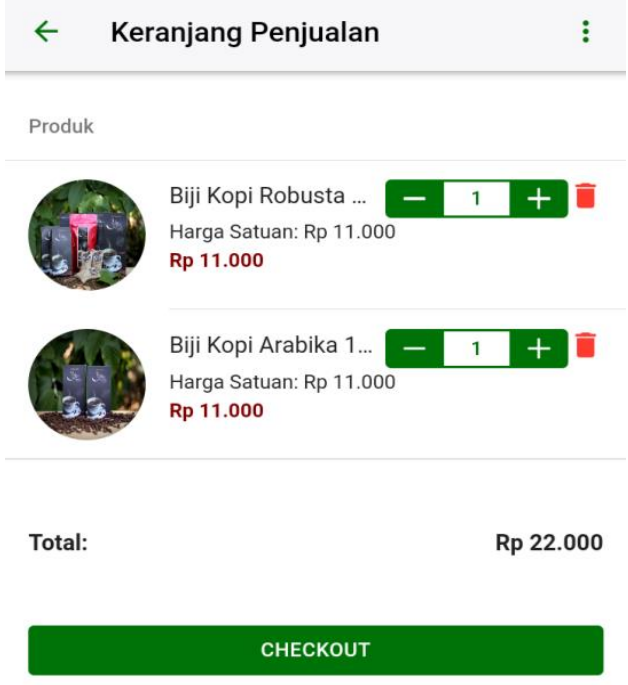

\section{Gambar 6. Halaman Home untuk Customer}

Pada halaman keranjang terdapat beberapa fungsi pada masing-masing yang akan dijelaskan sebagai berikut:

a.

$-1+1+$ Berfungsi untuk mengubah kuantitas produk yang akan dibeli.

b. Berfungsi untuk menghapus produk dalam keranjang.

Selanjutnya pengguna dapat melakukan checkout dengan cara mengklik tombol checkout yang terletak paling bawah menu. Setelah masuk pada menu checkout, pengguna harus mencantumkan alamat pengiriman agar proses transaksi dapat dilanjutkan, Gambar 7 menampilkan proses pengisian alamat. 


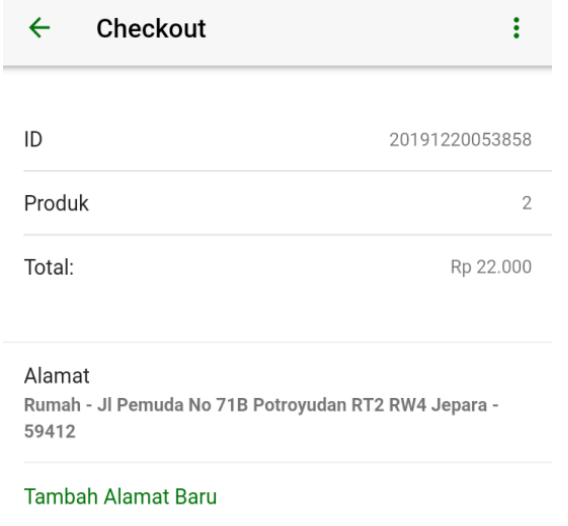

LANJUTKAN PEMBAYARAN

\section{Gambar 7. Halaman Checkout dan Pembayaran Customer}

Setelah sistem e-business jadi, langkah berikutnya adalah melakukan uji testing kepada responden akan kelayakan dari sistem yang telah dibangun. Adapun hasil pengujian terlihat pada Tabel 5.

Tabel 5. Hasil Pengujian Sistem

\begin{tabular}{clcc}
\hline No & \multicolumn{1}{c}{ Domain } & Nilai Rata-Rata & Keterangan \\
\hline 1 & Performance & 4,12 & Setuju \\
2 & Information & 4,16 & Setuju \\
3 & Economic & 3,02 & Ragu-Ragu \\
4 & Control and Security & 3,89 & Setuju \\
5 & Efficiency & 4,53 & Sangat Setuju \\
6 & Service & 3,78 & Setuju \\
\hline \multicolumn{4}{c}{ Rata-Rata } \\
& Tingkat Kepentingan & $\mathbf{3 , 9 2}$ & \\
\hline
\end{tabular}

Dari hasil analisis dengan PIECES Framework diperoleh hasil bahwa tingkat kepentingan penggunaan aplikasi e-business bernilai 3,92 yang artinya penting dalam pengimplementasian aplikasi $e$-business.

\section{KESIMPULAN}

Berdasarkan dari penelitian yang dilakukan, makan dapat ditarik kesimpulan sebagai berikut:

a. Penelitian ini menghasilkan sebuah produk berupa aplikasi e-business yang menangani tentang transaksi penjualan produk UMKM dan pengelolaan keuangannya. Dan aplikasi ini sudah terunggah di play store. 
b. Pengukuran kinerja sistem, menggunakan tools PIECES Framework yang terdiri dari 6 dimensi yaitu performance, information, economic, control and security, dan service. Pengukuran kinerja tersebut dilakukan dengan cara menyebarkan kuesioner kepada 50 responden dan diperoleh hasilnya adalah Kinerja dari aplikasi e-business ini mendapat skor 4,0 dengan tingkat kepentingan nya adalah Penting.

c. Selain itu, pengujian sistem juga dilakukan kepada ahli media untuk mengukur apakah sistem sudah berjalan dengan baik atau belum. Hasil pengujian tersebut mendapat skor 96,3\% yang dinyatakan Sangat Layak.

\section{DAFTAR PUSTAKA}

[1] S. S. Utami, "Pengaruh Teknologi Informasi Dalam Perkembangan Bisnis, Fakultas Ekonomi Universitas Slamet Riyadi Surakarta," J. Akunt. dan Sist. Teknol. Inf., vol. Vol. 8 No., pp. 6167, 2010.

[2] J. Jauhari, "Upaya Pengembangan Usaha Kecil Dan Menengah (UKM) Dengan Memanfaatkan E-Commerce,” J. Sist. Inf., vol. 2, no. 1, pp. 159-168, 2010.

[3] “Global Digital Report 2018," 2018.

[4] D. Chaffey, E-Business and Management E-Commerce, Fourth. London: Pearson Education Limited, 2009.

[5] G. S. Pranata dan Darma, "Strategi Penerapan E-Commerce Dalam Meningkatkan Keunggulan Bersaing," J. Manaj. dan Bisnis, vol. 11, no. 1, pp. 69-81, 2014.

[6] M. S. Raisinghani, L. Meade, and L. L. Schkade, "Strategic e-Business Decision Analysis Using the Analytic Network Process," IEEE Trans. Eng. Manag., vol. 54, no. 4, 2007.

[7] A. Supriyatna and V. Maria, "khazanah informatika Analisis Tingkat Kepuasan Pengguna dan Tingkat Kepentingan Penerapan Sistem Informasi DJP Online dengan Kerangka PIECES," J. Ilmu Komput. dan Inform., vol. 3, no. 2, pp. 88-94, 2017.

[8] W. Bentley, System Analysis \& Design Methods, Seventh. Mc Graw-Hill, 2007.

[9] N. Azizah and V. Pramandani, "Implementasi supply chain management pada umkm tenun troso jepara," NJCA, vol. 3 No.1, pp. 11-16, 2018. 